\title{
Nohutun Değişik Çeşit ve Nem Özelliklerine Göre Kırılma Karakteristiklerinin Belirlenmesi
}

\author{
Mustafa VATANDAŞ ${ }^{1} \quad$ Recai GÜRHAN ${ }^{1} \quad$ Mustafa ÇETIN $^{1}$
}

\author{
Geliș Tarihi: 03.10.2001
}

Özet: Bu çalıșmada beș farkı nohut çeșidinin sıkıștırma yükü altındaki mekanik davranıșı belirlenmiştir. Deneyler dört değişik nem seviyesi, uç farklı deformasyon hızı ve iki farklı yükleme ekseninde yapıımıştır. Deney sonuçları nem içeriğindeki artışın kırılma kuvvetini azaltırken deformasyon enerjisini artırdığını göstermiştir. Bunun yanında, deformasyon hızı arttıkça kırılma kuvveti artmakta; deformasyon enerjisi ise azalmaktadır.

Anahtar Kelimeler: nohut, kırilma kưveti, deformasyon enerjisi

\section{Determination of Cracking Characteristics of Chickpea According to Different Varieties and Moisture Levels}

\begin{abstract}
In this study, mechanical behaviour of five various chickpea varieties was determined under compression load. Tests were made for four moisture level, three deformation speeds and two loading axis. Experimental results showed that, moisture level decreases rupture force but increases deformation energy, However, deformation speed increases rupture force but decreases deformation energy.
\end{abstract}

Key Words : chickpea, rupture force, deformation energy

\section{Giriş}

Statik yada dinamik yük altında bulunan biyolojik materyaller, yapısal özelliklerine bağlı olarak tipik bazı davranışlar göstermektedirler. Bunlar akma yada kopma şeklinde ortaya çıkmaktadır. Uygulanan basma kuvveti biyolojik materyalin kısalmasına, çekme kuvveti ise uzamasına neden olmaktadır. Şekil 1'de görülen kuvvetdeformasyon eğrisi yardımıyla materyalin elastikiyet modalü, biyolojik akma sinıri, kopma noktası ve bu noktalara kadar oluşan kuvvet-deformasyon ve enerji değerleri belirlenebilmektedir.

Biyolojik akma noktası eğri üzerinde deformasyonda bir artışin $n_{\tau}$ kuvvette ise bir azalışın olduğu yada değişmenin olmadığı bir noktadır. Kopma noktası ise yük altındaki materyalin kırıldığı, çatladığı veya bozulmanın olduğu noktadır. Bu noktadan sonra kuvvette hızli bir azalma görülmektedir (Alayunt 2000, Gunasekaran and Paulsen 1985).

Tane materyalin fiziko-mekanik özelliklerinin belirlenmesinde sıkıştırma yükü altındaki davranışı özel bir önem taşımaktadır. Bu yolla kuvvet-deformasyon karakteristiğinin yanında, kırılma enerjisi de hesaplanabilmektedir. Elde edilen bu büyüklükler ekim, hasat ve hasat sonrasına ilişkin makine prosesleri yönünden temel tasarım parametrelerini oluşturmaktadır.

Oloso ve Clarke (1993), çalışmalarında Mahun cevizinin (cashew nuts) dayanım karakteristiklerini belirlemişlerdir. Sıkıştırma denemelerini farklı nem içeriği ve farkh yakleme yönlerinde gerçekleştirmişlerdir. Elde ettikleri sonuçlara göre en yŭksek kirilma enerjisi \%15 nem içeriğinde gerçekleşirken, en düşük enerji ise \%7,3 nem içeriğinde oluşmuştur. Diğer yandan en yüksek kırılma kuvveti $\% 7,3$, en düşük kırılma kuvveti $\% 13,4$ lük nem içeriğinde ortaya çıkmıştır.

Paulsen (1978), araştırmasında soyanın sıkıştırma yükü altındaki kırılma direncini belirlemiştir. Bu amaçla \%8, 11, 14 ve 17 nem içeriğindeki farkı çeşitleri, değişik deformasyon hızlarında yüklemiştir. Araştırmacı soyada nem içeriğinin $\% 8$ den $\% 17^{\prime}$ ye çıkmasıyla kabuğun kırılmaya başlaması için gerekli olan kuvvetin azaldığını belirtmiștir. Diğer yandan kırılma için gerekli enerjinin \%1114'lak nem aralığında maksimum olduğunu vurgulamıștır. Ayrıca kabuğun kınılmasında düşey hilum konumunda yüklenen tanelerin, yatay konumda yüklenenlerden daha az enerjiye gereksinimlerinin olduğunu belirtmiştir.

Waananen ve Okos (1988) araştırmalarında misır tanelerinin kırilma karakteristiklerini belirlemişlerdir. Araştırmacılar tanenin nem içeriğinin artışıyla kırılma gerilmesinin azaldığını, kırılma uzamasının ise arttığını belirtmişlerdir.

Zoerb ve Hall (1960), çalıșmalarinda, bezelye, misır ve buğday tanelerinin temel mekanik ve reolojik özelliklerini üç farklı deformasyon hızında ve çeșitli nem içeriklerinde ortaya koymuşlardir. Araştırmacılar tanenin dayanım özelliklerini arttıran en önemli faktörün nem içeriği 


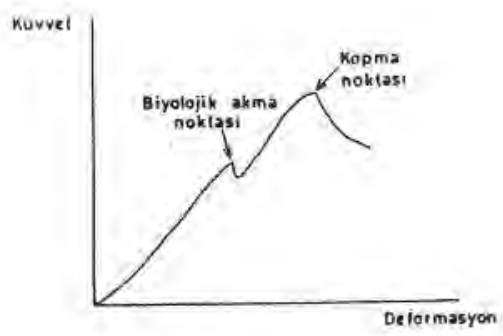

Şekil 1. Biyolojik materyalde kuvvet-deformasyon eğrisi (Alayunt 2000)

olduğunu belirterek, nem içeriğindeki artışın sıkıştırma dayanımı, elastikiyet modülü, maksimum sıkıştırma gerilmesini ve kesme gerilmesini azalttığını belirtmişlerdir. Enerji gereksinimlerinin ise nem içeriğindeki artışla birlikte yŭkselme gösterdiğini bildirmişlerdir. Elastiklik sınırına kadar maksimum deformasyon kuwetinin ve maksimum dayanimın, nem içeriğinin artışı ile azaldığını vurgulamışlardır.

Bu çalışmada; Türkiye tarımında yemeklik tane baklagiller içinde ekim alanı bakımından 1999 verilerine göre (Anonim 2001) \%40'lık gibi önemli bir paya sahip olan nohutun ekiminden tăketimine kadarki süreç içerisinde karşılaşabileceği fiziksel etkiler karşısındaki mekanik davranışının ortaya konulması amaçlanmıştır.

\section{Materyal ve Yöntem}

Araştırmada, Türkiye de yetiştirilen beş farklı nohut çeşidi kullanılmıştır. Denemeler dört değişik nem, uç farklı deformasyon hızı ve ikj farklı eksende tanelerin paralel plakalar arasında sıkıştııılmasıyla gerçekleştirilmiştir. Çizelge 1'de çeşitlerin bazi özellikleri Şekil 2 'de ise materyal sıkıștırma eksenleri, verilmiştir.

Denemelerde kullanılan nohut taneleri \%4-5 doğal nem oranında temin edilmiş, bunların bir kısmı fıında kurutularak $\% 0$ nem değerine indirilmiştir. Diğer taneler ise higroskopik olarak $\% 5,10$ ve $1^{\prime}$ 'lik nem değerlerine koşullandırılarak denemelerden önce minimum 48 saat suresince nem dengelenmesi için süre tanınmıştır. Nem değerleri 24 saat süreyle $105^{\circ} \mathrm{C}^{\prime}$ de örneklerin kurutulmasıyla belirlenmiştir (Paulsen 1978). Denemeye alınan nohut örneklerinde çatlak veya kırık gibi fiziksel kusurlar olmamasına dikkat edilmiştir. Deneyler her nem düzeyi, deformasyon hızı, yükleme ekseni ve çeşit için 5 tekerrürlü olarak yapılmıştır. Deformasyon hızı değerieri $1,35,4,69$, $7,50 \mathrm{~cm} / \mathrm{min}$ olarak alınmıştır. Tanelerin yüklenmesi $x-x$ ve $y-y$ eksenlerinde gerçekleștirilmiştir. Bu amaçla biri sabit diğeri hareketli iki paralel plaka kullanılmıştır. Deneme dazzeninin şematik göronäuma Şekil 3' de verilmiştir.

Denemeler sırasında plakalar arasındaki tanelere uygulanan kuvvet bir yazıcı kullanılarak kuvvet-zaman eğrisi olarak elde edilmiș daha sonra bu eğriler kuvvetdeformasyon eğrisine dönüştürülmüştür. Elde edilen bu eğriler altında kalan alan elektronik bir planimetre kullanılarak okunmuş ve enerji değerleri belirlenmiştir.

\section{Bulgular ve Tartışma}

Nohut tanesine ilişkin tipik kırııma eğrileri Şekil $4^{\prime}$ de görülmektedir. Eğri, Akçin-91 çeşidinde 1,35 cm/min deformasyon hızinda $y$-y konumunda elde edilmiştir. Grafikte dușey eksen bölüntüleri 9,06 N' luk kưveti, yatay eksen bölantaleri ise $0,48 \mathrm{~mm}$ 'lik deformasyonu veya $2,1 \mathrm{~s}$ ' lik zamanı göstermektedir.

Çeşitlerin ortalaması alınarak düzenlenmiş maksimum kuvvet-nem içeriği grafikleri $x-x$ ve $y$-y eksenlerine göre Şekil 5 ve 6 'da verilmiştir.

\section{Çizelge 1. Nohut çeşitlerinin bazı özellikleri}

\begin{tabular}{|l|c|c|c|c|}
\hline \multirow{2}{*}{ Çeşit } & \multicolumn{3}{|c|}{ Ortalama boyutlar (mm) } & \multirow{2}{*}{$\begin{array}{c}\text { Firın kuru } \\
\text { durumda 1000 } \\
\text { tane ağırığı (gr) }\end{array}$} \\
\cline { 2 - 4 } & Kalıniık & Genişlik & Uzunluk & \\
\hline Er-99 & 7,5 & 8,1 & 10,1 & 397,0 \\
\hline Akçin-91 & 7,4 & 7,4 & 9,4 & 332,4 \\
\hline Küsmen & 7,8 & 7,7 & 10,7 & 376,2 \\
\hline Gökçe & 7,6 & 7,4 & 10,2 & 369,2 \\
\hline Uzunlu-99 & 7,8 & 7,6 & 10,3 & 454,8 \\
\hline
\end{tabular}

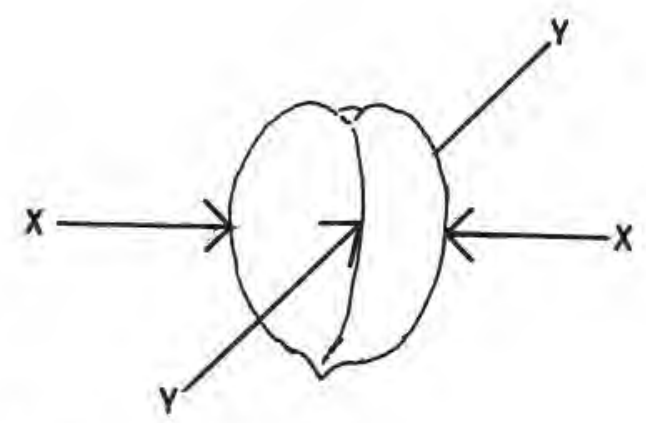

Şekil 2. Materyal sıkıştırma eksenieri

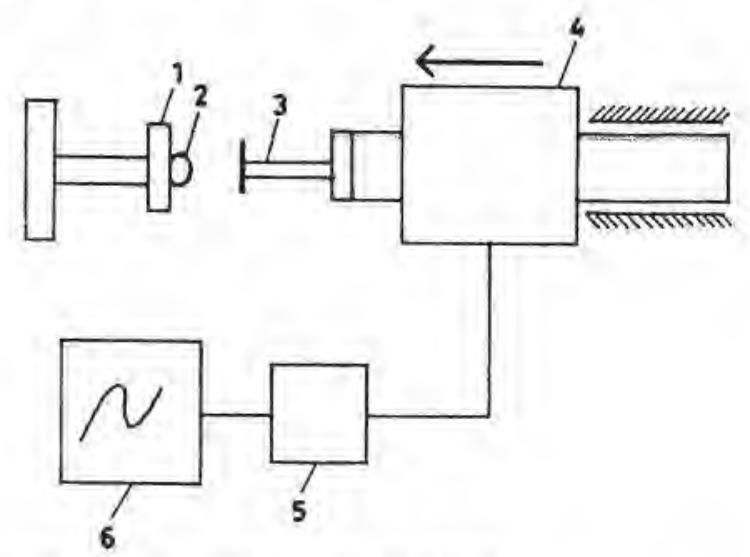

Şekil 3, Deneme düzeninin șematik görünümü

(1,Sabit tutucu, 2.Nohut, 3.Hareketil sıkıştırma plakası, 4.Dinamometre 5. Amplifkatôr, $6 . X-Y$ yazıcı) 
Şekillerin incelenmesinden de görüleceği gibi her iki eksende de nem içeriği arttıkça kırılmayı başlatan kuvvet değeri genel bir azalma göstermektedir. Bu değer $y-y$ ekseninde, $x-x$ eksenine göre tüm deformasyon hızlarında daha yüksek olarak elde edilmektedir.

Aynı deformasyon hızında $(1,35 \mathrm{~cm} / \mathrm{min})$ çeşitlere göre nem içeriğine bağlı olarak elde edilen maksimum kuvvet değerlerinin değişimi ise Şekil 7 ve $8^{\prime} \mathrm{de}$ görülmektedir. Burada da tüm çeşitlerde nem içeriğinin artışıyla her iki eksende de maksimum kuvvette genel bir azalış eğilimi belirlenmiştir. Ayrıca Gökçe ve Er-99 çeşitlerinin diğerlerine göre daha büyük kırılma direnci gösterdiği izlenebilmektedir.

Aynı nem içeriğinde (\%10) tüm çeşitlerin deformasyon hızına bağlı maksimum kırıma kuvveti gereksinimleri ise Şekil 9 ve 10 'da görülmektedir. Her iki konumda da deformasyon hızı arttıkça kırılma kuvveti gereksiniminin genel bir artış eğilimi gösterdiği izlenmektedir. Diğer yandan Gökçe çeşidinin tüm deformasyon hızlarında en yüksek kırılma direnci gösterdiği belirlenmiştir.

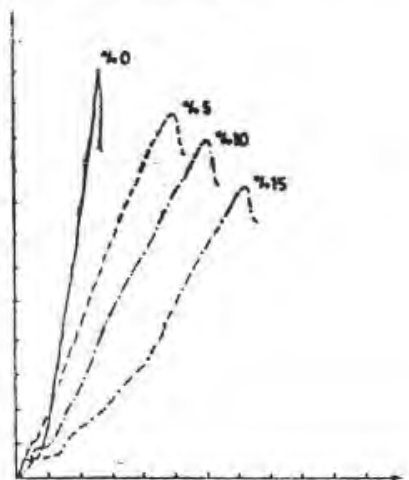

Șekil 4. Kırılma eğrileri

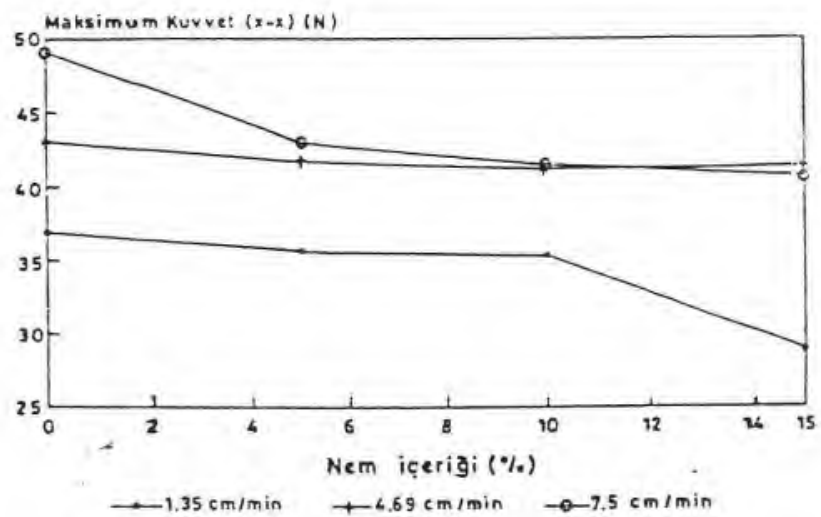

Şekil 5. Çeşitler ortalamasına göre $x-x$ ekseninde maksimum kuvvet-nem içeriğinin deformasyon hızlarına göre değişimi

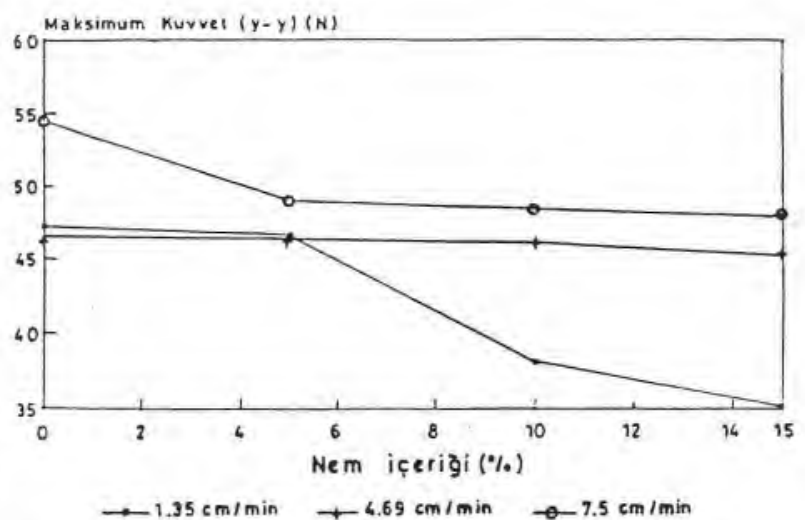

Şekil 6. Çeşitler ortalamasına göre $y-y$ ekseninde maksimum kuvvet-nem içeriğinin deformasyon hızlarına göre değişimi

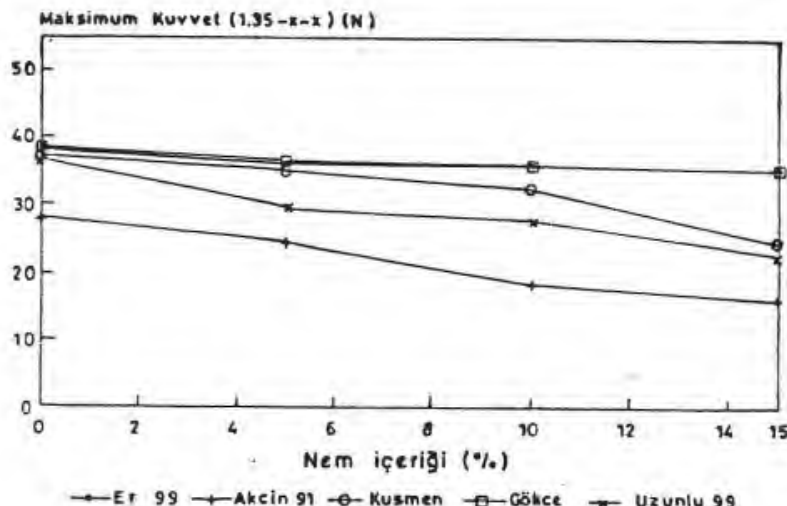

Șekil 7. $1,35 \mathrm{~cm} / \mathrm{min}$ 'lik deformasyon hızında $x-x$ ekseninde çeşitlere göre nem içeriğine bağlı olarak maksimum kuvvet değerlerinin değişimi

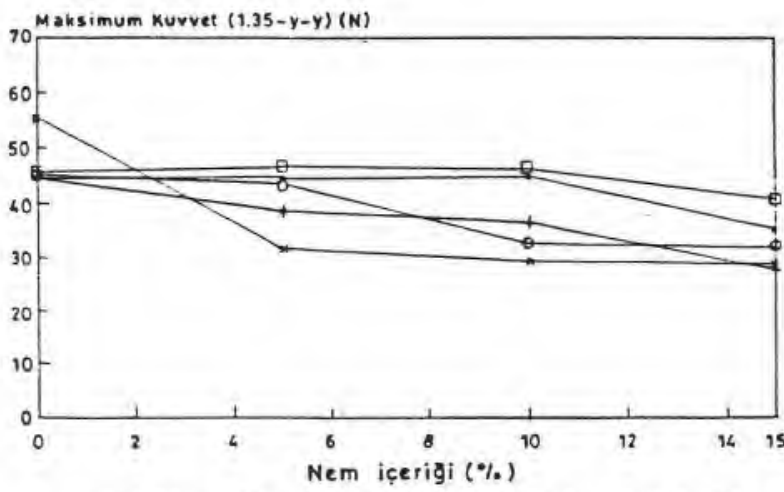

$\rightarrow$ Er $99+$ Akcin 91 -kusmen $\theta$-Gökce \#-Uzunlu 99

Şekil $8.1,35 \mathrm{~cm} / \mathrm{min}$ 'lik deformasyon hızında $y$-y ekseninde çeşitlere göre nem içeriğine bağlı olarak maksimum kuvvet değerlerinin değişimi 


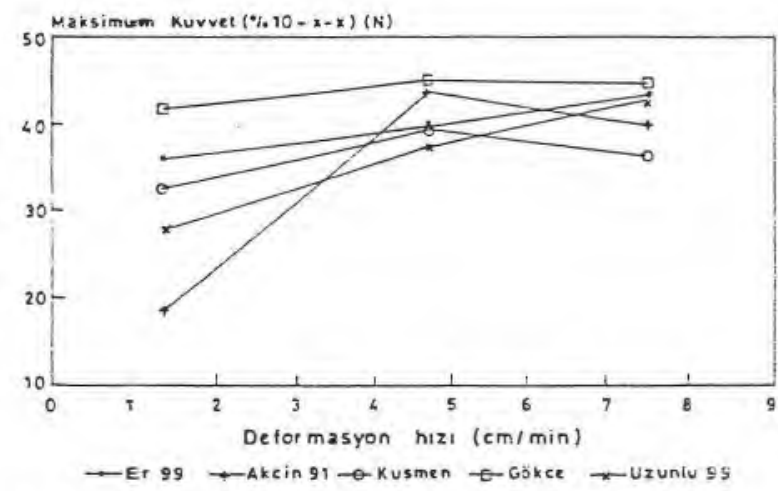

Şekil 9. \%10 nem içeriğinde $x$-x ekseninde deformasyon hızına bağı maksimum kuvvet değerlerinin değişimi

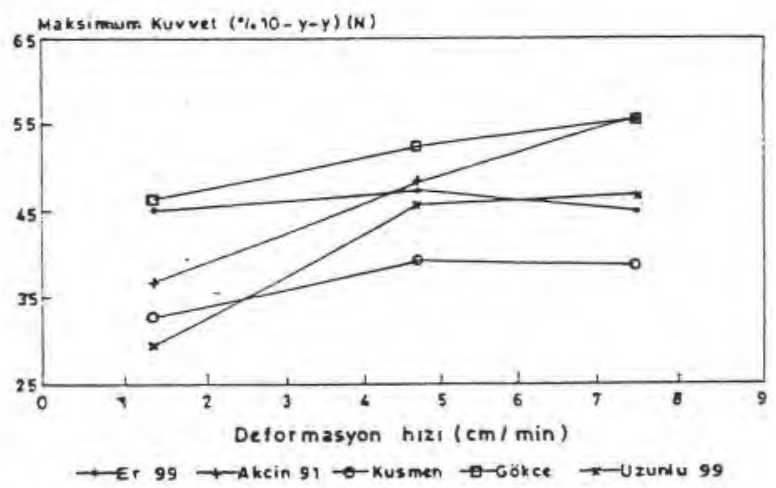

Şekil 10. \%10 nem içeriğinde $y$-y ekseninde deformasyon hızına bağlı maksimum kuvvet değerlerinin değişimi

Deformasyon enerjisi için elde edilen bulguların grafik olarak gösterimleri çeşitler ortalamasına göre Şekil 11 ve 12 ' de verilmiştir. Bu şekillerin incelenmesiyle nem içeriği artışının deformasyon enerjisinde logaritmik bir artışa yol açtığı görülmektedir. Aynı zamanda deformasyon hızındaki artışın deformasyon enerjisinde genel bir artışa neden olduğu da izlenebilmektedir. Bu artış \%10 düzeyine kadar daha belirgin olmakta, bu nem düzeyinin üzerinde ise daha yatay bir seyir göstermektedir.

Aynı deformasyon hızında $(4,69 \mathrm{~cm} / \mathrm{min})$ çeşitlere göre nem içeriğine bağlı olarak elde edilen deformasyon enerjisi değerlerinin değişimi Şekil 13 ve $14^{\prime} \mathrm{de}$ görülmektedir. Şekillerde nem içeriği artışının deformasyon enerjisinde genel bir artışa neden olduğu izlenebilmektedir. Özellikle \%10 nem içeriğinde bu artışın en büyük değerine ulaştığı ve bunun da Akçin-91 çeşidinde elde edildiği görülebilmektedir.

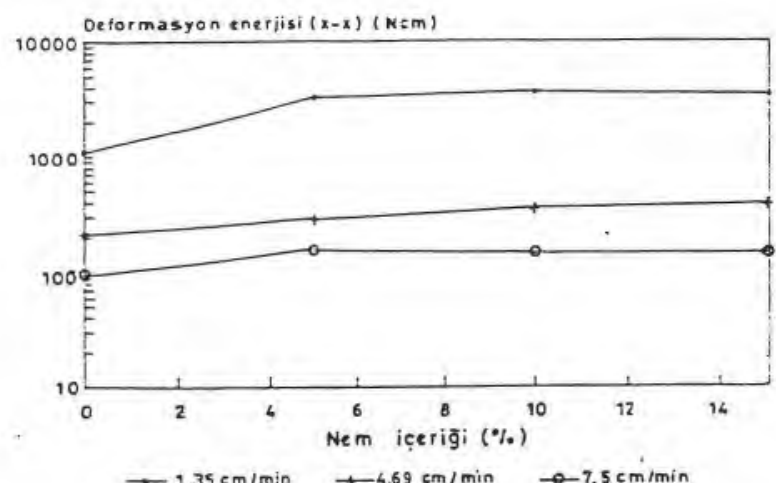

Şekil 11. Çeşitler ortalamasına göre $x-x$ ekseninde nem içeriğine bağlı olarak deformasyon enerjisi değerinin değişimi

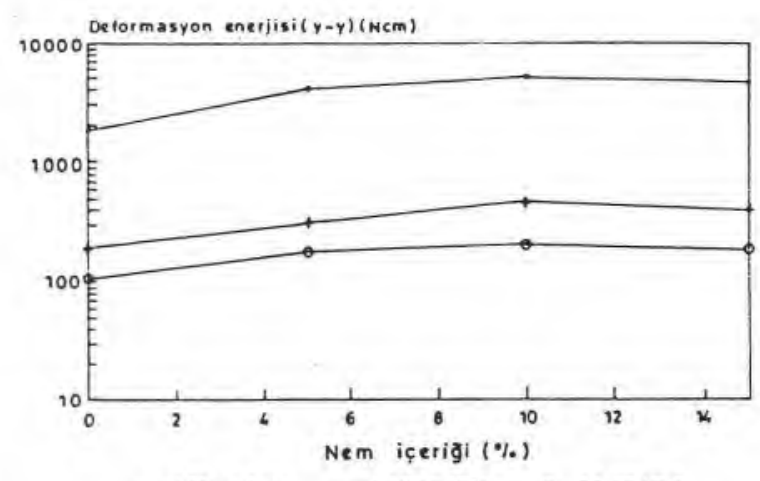

$-1.35 \mathrm{~cm} / \mathrm{min}+6.69 \mathrm{~cm} / \mathrm{min} a-7.5 \mathrm{~cm} / \mathrm{min}$

Şekil 12. Çeșitler ortalamasına göre $y-y$ ekseninde nem içeriğine bağlı olarak deformasyon enerjisi değerinin değişimi

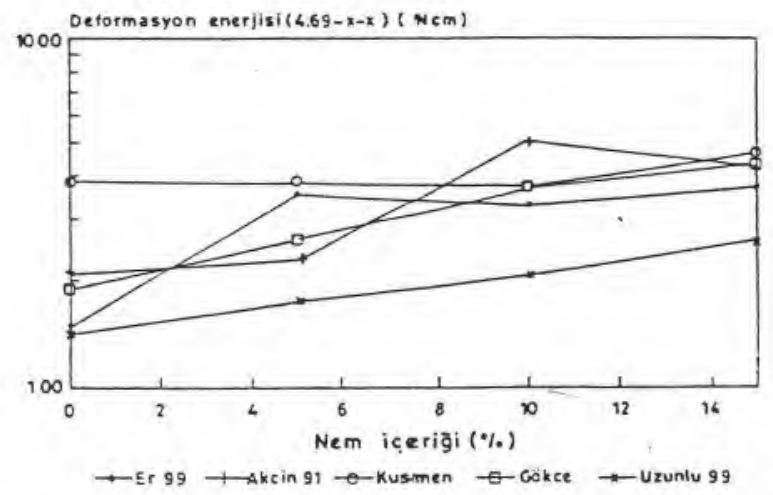

Şekil 13. $4,69 \mathrm{~cm} / \mathrm{min}$ deformasyon hızında nem içeriğine bağlı olarak $x-x$ ekseninde deformasyon enerjisi değerlerinin değişimi 
Aynı nem içeriğinde $(\% 10)$ çeşitlere göre deformasyon hızina bağlı deformasyon enerjisi değişimleri ise Şekil 15 ve 16 'de görülebilmektedir. Bu şekillerde de deformasyon hiziyla deformasyon enerjisi arasinda logaritmik olarak azalan bir ilişki belirlenmiștir.

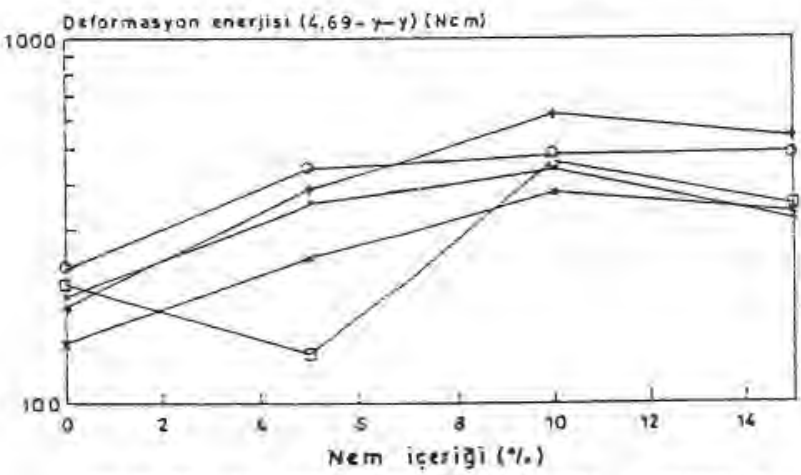

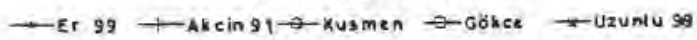

Șekil 14. 4,69 cm/min deformasyon hızında nem içeriğine bağlı olarak $y-y$ ekseninde deformasyon enerjisi değerlerinin değișimi

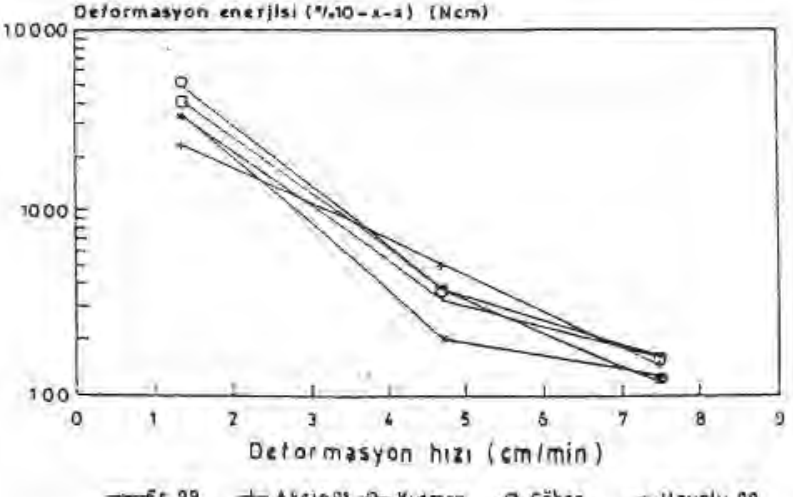

Sekil 15. \%10 nem içeriğinde $x-x$ ekseninde deformasyon hızına bağlı deformasyon enerjisi değerlerinin değișimi

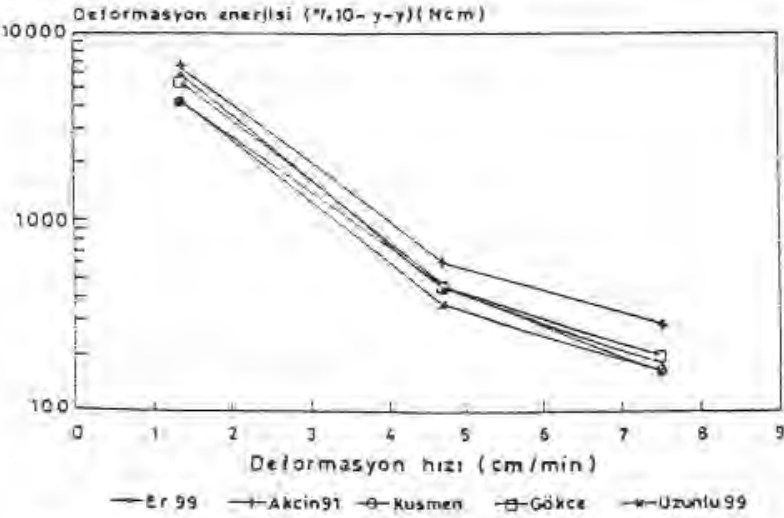

Şekil 16. \%10 nem içeriğinde $y$-y ekseninde deformasyon hızına bağlı deformasyon enerjisi değerlerinin değișimi

\section{Sonuç}

Tüm verilerin istatistiki değerlendirilmesi sonucunda aşağıdaki sonuçlar elde edilmiştir.

1. Nohut çeşitlerinde nem ve hız faktörleri arasında maksimum kuwvet yönünden varyans analizi yapıldığında, en yüksek değer Er-99 çeșidi için \%5'lik nem içeriğinde, Akçin-91 çeşidi için tam kuruda, Küsmen çeşidinde tam kuru ve \%5'lik nem seviyesinde, Uzunlu çeșidinde tam kuru nem düzeyinde elde edilmiştir. Gökçe çeșidinde ise tüm nem içeriklerinde maksimum kuwet yönünden farkın önemli olmadığı sonucuna varılmıştır.

2. Maksimum kuwvet için nohut çeşitlerinde deformasyon hizlarına göre yapılan değerlendirmede ise Er-99 için $7,50 \mathrm{~cm} / \mathrm{min}$, Küsmen için 4,69 ve $7,50 \mathrm{~cm} / \mathrm{min}$ de en büyük değerler elde edilmiștir. Ancak bu iki hiz değeri arasında önemli bir fark bulunamamıştır. Gökçe çeşidi için en büyûk kuwvet gereksinimi $4,69 \mathrm{~cm} / \mathrm{min}$ ile $7,50 \mathrm{~cm} / \mathrm{min}$ değerlerinde elde edilirken benzer durum Akçin-91 çeşidi içinde gözlenmiştir. Uzunlu-99 çeşidinde ise en bŭyük değer $7,50 \mathrm{~cm} / \mathrm{min}^{\prime}$ de elde edilmiştir.

3. Maksimum kuvvet için nem ve deformasyon hızı etkileşiminde en yüksek kuvvet değerinin tam kuruda 7,50 $\mathrm{cm} / \mathrm{min}$ ' lik deformasyon hızında elde edilirken, $\% 5, \% 10$ ve $\% 15$ nem seviyelerinde ise en yaksek kuvvet değerinin $4,69 \mathrm{~cm} / \mathrm{min}$ ve $7,50 \mathrm{~cm} / \mathrm{min}^{\prime}$ lik ilerleme hizında elde edilmiştir.

4. Maksimum kuvvet için çeşit ve yükleme ekseni yönünden yapilan analizlerde tüm çeşitler için $Y-Y$ eksenindeki yüklemelerde herhangi bir fark bulunmamıştır.

5. Yapilan varyans analizi sonucunda, deformasyon enerjisi üzerinde nem içeriği ve deformasyon hiz parametrelerinin etkisi önemli bulunmuştur $(p<0,01)$. Buna bağlı olarak yapilan Duncan testi sonucunda ise, her nem seviyesinde $1,35 \mathrm{~cm} / \mathrm{min}$ 'lik deformasyon hızı değerinin en yūksek deformasyon enerjisi gereksinimine ihtiyaç duyduğu belirlenmiştir.

6. Nohut çeșitleri nem içeriği ve yükleme eksenlerine göre varyans analizine tabi tutulduğunda her iki parametre yönunden de farkıılıkların önemli olduğu belirlenmişstir $(p<0,01)$. Duncan testi sonuçları ise $Y-Y$ ekseninde Küsmen ve Uzunlu-99 çeșitlerinin deformasyon hız। parametrelerine bağlı olarak aralarındaki farkın önemli olduğunu göstermiştir. X-X yŭkleme ekseninde ise Gökçe ve Akçin-91 nohut çeşitlerinin en yüksek deformasyon enerjisine gereksinim duydukları görülmüştür.

7. Yükleme eksenleriyle deformasyon hızları arasındaki etkileşim tüm çeşittlerde istatistiki olarak önemli bulunmuştur.Ancak $X-X$ yükleme ekseninde $1,35 \mathrm{~cm} / \mathrm{min}$ 'lik deformasyon hizı seviyesinde en yŭksek deformasyon enerjisi elde edilmiştir. Aynı durumun $Y-Y$ yükleme ekseni içinde geçerli olduğu görülmüştür. 


\section{Kaynaklar}

Anonim, 2001. Tarım İstatistikleri Özeti. 1980-1999. Başbakanlık Devlet istatistik Enstitüsü Yayınları, Ankara.

Alayunt, F. N. 2000. Biyolojik Malzeme Bilgisi. Ege Üniv. Ziraat Fak. Yayınları, No:541, Izmir.

Gunasekaran, S. and M. R. Paulsen, 1985. Breakage resistance of corn as a function of drying rates. Transaction of the ASAE, 28 (6) 2071-2076.

Paulsen, M. R. 1978. Fracture resistance of soyabeans to compressive loading. Transaction of the ASAE, 21 (6) 1210-1216.
Oloso, A. O. and B. Clarke, 1993. Some aspects of strength properties of cashew nuts. J. of Agric. Eng. Res., 55, 27-43.

Zoerb, G. C. and C. W. Hall, 1960. Some mechanical and rheological properties of grains. J. of Agric. Eng. Res. $55,27-43$.

Waananen, K. M. and M. R., Olcos, 1988. Failure properties of yellow-dent corn kernels. Transaction of the ASAE, 31 (6) 1816-1827. 